\title{
Perspectives of Frontline Professionals on Palestinian Children Living with Sibling and Parental Drug Use in the West Bank and Gaza Strip
}

\author{
Mohammed Al-Afifi ${ }^{1}$ - Leen Abushams ${ }^{2}$ - Mazen Sakka ${ }^{1} \cdot$ Maha Shehada $^{1}$. \\ Riad Afifi ${ }^{1}$ - Majed Alloush ${ }^{3}$ - Afaf Rabee ${ }^{3} \cdot$ Stephanie Kewley $^{4} \cdot$ Zara Quigg $^{5}$. \\ Mark Whitfield ${ }^{5} \cdot \operatorname{Jim}$ McVeigh $^{5} \cdot$ Mayyada Wazaify $^{2} \cdot$ Marie Claire Van Hout $^{5}$ (D)
}

Published online: 30 August 2019

(C) The Author(s) 2019

\begin{abstract}
The Occupied Territories of Palestine (OtP) consists of the non-contiguous West Bank including East Jerusalem, and the Gaza Strip. Political and economic tensions and its dense populations compound the impact of drug abuse and addiction in the home. A qualitative study using four focus groups $(n=42)$ was conducted in West Bank and Gaza Strip explored the experiences of professionals working with Palestinian families and children affected by substance use and addiction in the home. Data were analysed using thematic analysis (TA), and four themes emerged. These were 'The rising and shifting problem of drug use in Palestine'; 'Psychosocial causal factors of drug use in Palestine'; 'The consequences for children and families living with drug use'; and 'Potential solutions to the problem are complex and multi-faceted.' The study paints a concerning picture of how drug abuse impacts on Palestinian families subjected to multiple pressures, stigmas, risks and harms relating to their situation.
\end{abstract}

Keywords Children · Parents · Siblings · Drugs · Palestine $\cdot$ Gaza $\cdot$ West Bank · Jerusalem · Palestine $\cdot$ Substance abuse

\section{Background}

The Occupied Territories of Palestine (OtP) consists of the non-contiguous West Bank with an area of $3000 \mathrm{~km}^{2}$ and a population of three million, and the Gaza Strip with an area of $262 \mathrm{~km}^{2}$ and a population of two million. According to the United Nations Relief and Works Agency for Palestine Refugees in the Near East (UNRWA), 26.6\% are refugees living in 19 camps in the West Bank and Jerusalem, while in the Gaza Strip, $66.2 \%$ are refugees living in eight densely populated camps. The crude birth rate in Palestine is 30.5 per thousand, and about

Marie Claire Van Hout m.c.vanhout@ljmu.ac.uk

Extended author information available on the last page of the article 
$40 \%$ of refugees are children (Waterston and Nasser 2017). The Al-Aqsa uprising in 2000 resulted in a significant rise in individual and community stress, economic hardship, exposure to political violence, school closures and travel restrictions (Massad et al. 2016). In Gaza Strip, the frequent wars and escalations including the war in 2014 lasted 51 days had resulted in a high number of causalities, fatalities, trauma and fear (Al-Afifi et al. 2015). High unemployment and poverty prevail in both areas, particularly in the Gaza Strip (Palestinian Central Bureau of Statistics (PCBS) 2018).

Conditions in the Gaza Strip and the West Bank have facilitated an exponential rise in drug trafficking, drug use and addiction among Palestinians, with increasing prevalence of illicit, new psychoactive substance (NPS), over the counter (OTC) and prescription drug abuse observed among youth, Palestinian women and family members of current drug users (Palestinian National Institute of Public Health 2017a, b; Damiri et al. 2018b; Sweileh et al. 2004). These observed increases have occurred despite religious, legal and cultural constraints. The stigma of addiction across the OtP is significant (Damiri et al. 2018a; Van Hout et al. 2019; Defense for Children International/Palestine Section 2007). Recent situational assessments conducted in 2017 have reported that drug trends include marijuana, prescription medications (anti-depressants, Z-hypnotics, benzodiazepines and analgesics) and novel psychoactive substances (NPS) ('Sintetique Marijuana'), with reported high dose use of methadone, morphine, phencyclidine, barbiturates, benzodiazepines and synthetic opioids such as tramadol, and gabapentinoid drugs such as pregabalin (Palestinian National Institute of Public Health 2017a). Damiri et al. (2018b) reported that in 2018, on the rise since 2013 of trafficking and use of NPS, particularly synthetic cannabinoids, the manufacture of liquid amphetamine and the cultivation of marijuana in the OtP.

The 2017 situational assessments estimate that there are now over 80,000 drug users in the OtP, of which 26,500 are high-risk drug users (Palestinian National Institute of Public Health 2017a). Children and young people are particularly at risk of substance abuse and are vulnerable to physical and sexual abuse, exploitation in drug trafficking and at risk of becoming addicts themselves (Defense for Children International/Palestine Section 2006; Palestinian National Institute of Public Health 2017b; Damiri et al. 2018a; Van Hout et al. 2019). Drug-related risk behaviours are higher among males, older youth, in urban areas and refugee camps (Thabet and Dajani 2012; Glick et al. 2018). There has been a sharp increase in familial poverty, children dropping out of school and becoming caregivers, becoming street children by either begging or working with little income, and are at high risk of exploitation (Van Hout et al. 2019). There is potential for drug exposed and traumatised Palestinian children to use drugs themselves, become dependent and their risk of overdose, psychiatric events and HIV/hepatitis C acquisition (Van Hout et al. 2019).

The Palestinian National High Committee for the Prevention of Drugs and Psychotropic Substances recognises drug dependence as a multi-factorial health disorder and addressing drug dependence as a disease is highlighted in the past two Palestinian National Health Strategies. The right to health was included in the current Palestinian Drug Law which states the drug addict is a patient and should have the opportunity to access treatment services. Most recently in 2019, the Palestinian Ministry of Health with technical support from the United Nations Office on Drugs and Crime Programme Office in the OtP (UNODC-POPSE) has responded to the growing problem of drug dependence and HIV/hepatitis $\mathrm{C}$, and has established the Palestinian National Rehabilitation Centre (PNRC) based in Bethlehem, West Bank (United Nations Office for Drugs and Crime (UNODC) 2019). This is an encouraging step forward for the West Bank, and yet leaves the Gaza Strip behind, without a treatment 
facility and struggling to deal with the societal issue of drug abuse in Palestinian families. A greater insight into the experiences of families and children affected by substance use in Palestine is warranted (Van Hout et al. 2019). In order to better understand their needs, the study aimed to explore the perspectives of professionals working with international organisations, non-governmental organisations and government who provide drug treatment to Palestinian families in the West Bank and the Gaza Strip.

\section{Methods}

A focus group study was conducted in West Bank and Gaza Strip to explore the experiences and knowledge of professionals working with Palestinian families and children affected by substance use and addiction in the home. It was undertaken by an international multidisciplinary research team. Ethical approval for the study was granted by the University Ethics Committee at Liverpool John Moores University, UK (approval number 19/PHI/005) with further ethical approval granted by the Deanship of Scientific Research at the University of Jordan, Jordan (approval number 413/2019/19) and the ethics committee at the SARC Gaza, Palestine (approval number R-A-01- 2019).

The design of the focus group guide was based on research expertise in the field, existing work by team members in both the Gaza Strip and the West Bank and on a systematic review of literature conducted by the team (Van Hout et al. 2019). Participants were recruited purposively through face-to-face, telephone and email strategies (Etikan et al. 2016). Eligibility criteria meant that all participants were over the age of 18 and employed or studying/ researching in professional roles and subjects that would bring them into contact with Palestinian families and children affected by substance use and addiction. Potential participants were sent an information sheet about the study and offered an opportunity to ask further questions about the study before agreeing to participate. Before participating, participants signed a consent form. Participants did not receive any incentive or compensation for participation.

Focus groups were conducted by two members of the team, a facilitator and co-facilitator, were audio recorded and supported by note taking. Open-ended questions (Smithson 2000; Kallio et al. 2016) were posited by the focus group facilitator. Participants were asked to describe the following: 'the current situation with regard to substance abuse and addiction in Gaza or West Bank'; 'how this situation has changed over time'; 'how this currently affects Palestinian families and children'. In addition to discussion focusing on the current status of drug use and addiction in the Gaza Strip or the West Bank, the facilitator also explored participants thoughts around possible community and psychosocial interventions needed to reduce the vulnerability of children exposed to substance use in the Gaza Strip or the West Bank, and how non-governmental organisations (NGOs) might better support Palestinian families and children affected by substance use and addiction, was also asked. All focus groups were audio recorded and fully transcribed into Arabic, and then translated into English by the second author. This was cross-checked for accuracy by the lead author, prior to analysis.

Data were analysed using thematic analysis (TA) (Braun et al. 2019). This approach was deemed suited to garner in depth understanding of the impacts of familial drug abuse within the multifaceted socio-political context of Palestine. It underpins phenomenological examination of the experiences of professionals working with Palestinian families and children, from a range of multi-disciplinary perspectives, realities and meanings, due to its mitigation of 
potential cultural and language misinterpretation, and appreciation of the complex social contexts and challenges faced by participants (Nowell et al. 2017; Braun and Clarke 2006; Clarke and Braun 2018).

In order to ensure scientific rigour, a quality framework in analysis was used (Braun and Clarke 2006). This involved several key steps: (1) reading and rereading the transcription, individually and in pairs to note early ideas; (2) coding in a systematic and logical manner using a data-driven approach supported by NVivo version 12, and paying attention to interesting concepts and ideas within the data; (3) organisation of codes into corresponding groups using an iterative process in developing themes and subthemes; (4) refining and reviewing of themes by the team as a collective in terms of internal homogeneity and external heterogeneity, examination of coherence of patterns across themes and development of a thematic map; and (5) final clear definition and naming of themes, with data extracts representing and articulating the essence of the theme, and overall analysis.

\section{Results}

Four focus groups were undertaken across the Gaza Strip and the West Bank. A total of 42 participants took part $(M=10.5 S D=2.5)$, each focus group lasted on average $89 \min (S D=$ 13.9). Table 1 provides an overview of participants' demographics and focus group details, and Fig. 1, a thematic map of analysis.

\section{The Rising and Shifting Problem of Drug Use in Palestine}

Across all focus groups, concerns for the increasing prevalence of drug use and addiction within Palestine communities were reported. The reported increase in drug use and addiction appears to have been a rapid phenomenon. In the Jerusalem focus group, participants reported that since 2015, addiction 'has risen with [sic] about 200\%' (Male Anti-Drug Authority Officer) particularly with synthetic cannabinoids, and NPS such as 'Hydro' for which professionals in Jerusalem asserted that '95\% of the cases seeking treatment and advice are addicted to it' (Male Psychologist). Gender differences were also reported, with male Palestinians reported to engage in drug use at a greater rate compared with females although these reports cannot be fully relied upon, as one participant in the Gaza Strip focus group observed that 'drug use is spreading among females but concealed because of the stigma' (Male Social worker from Middle Camps).

The prevalence of the type of drug consumed in the OtP was also discussed. The Bethlehem focus group noted 'the Palestinian market is like any market, heroin exists, hashish, crystal, ecstasy, trip, patches/stamps and medical marijuana with 100 NIS/gram, it all exists and [is] very similar to the Israeli market' (Male Anti-Drug Authority Officer). Consistent across all discussions was the reported use of tramadol, and particularly the Gaza Strip focus group where this opioid was reported to be 'the most commonly used'. Identified across all discussions was the observation that the choice of drug depends upon availability; once the market has consumed one supply, a new substance surfaces, creating new demand. This was raised in the Ramallah focus group as 'hydro [synthetic cannabinoids], nice guy [synthetic cannabinoids] and marijuana have been trendy for a long time, but when people became aware [of the harms], they retreated and turned to pills' (Male Anti-Drug Authority Officer). The Jerusalem focus group also reported a shift toward synthetic cannabinoids stating they recently 


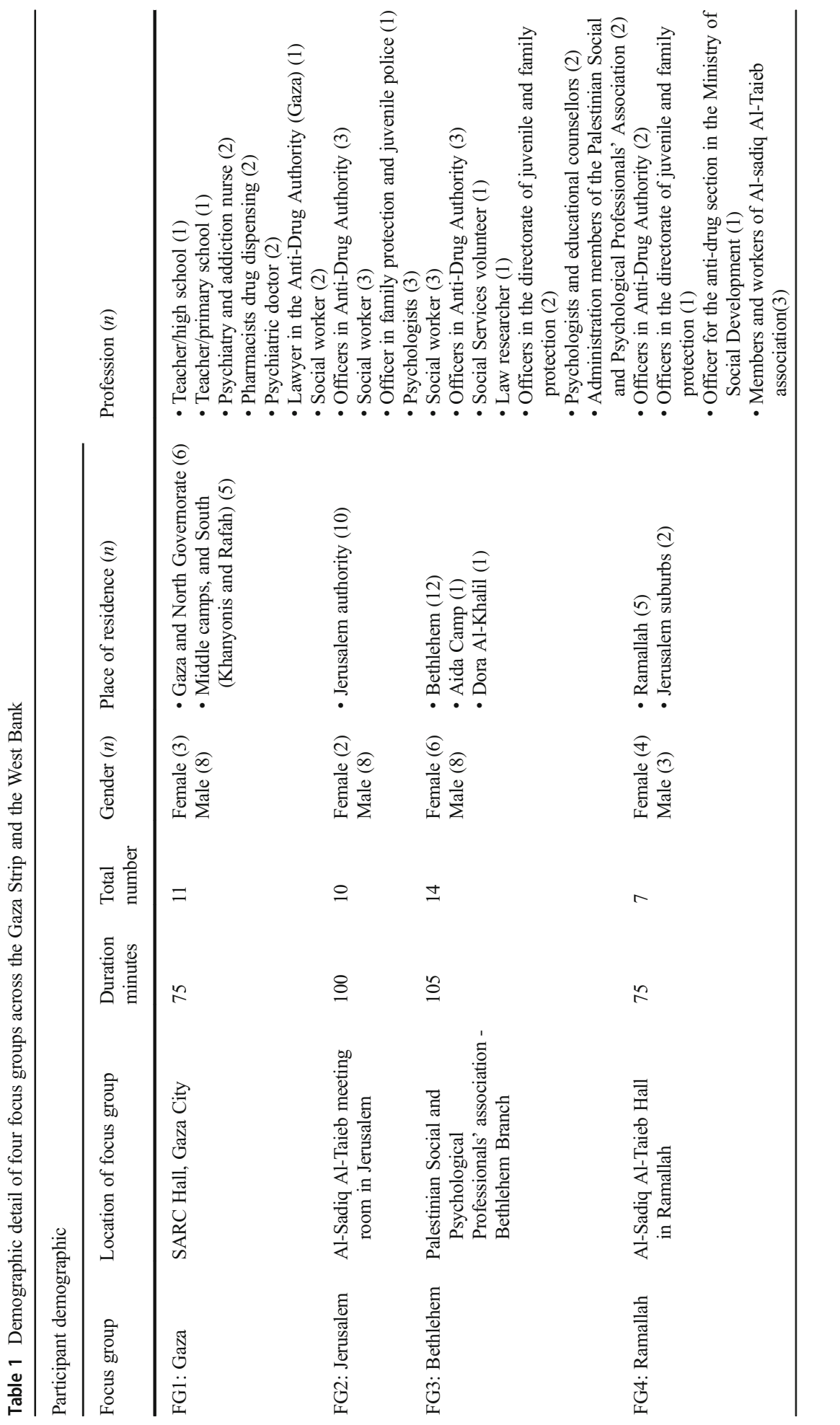




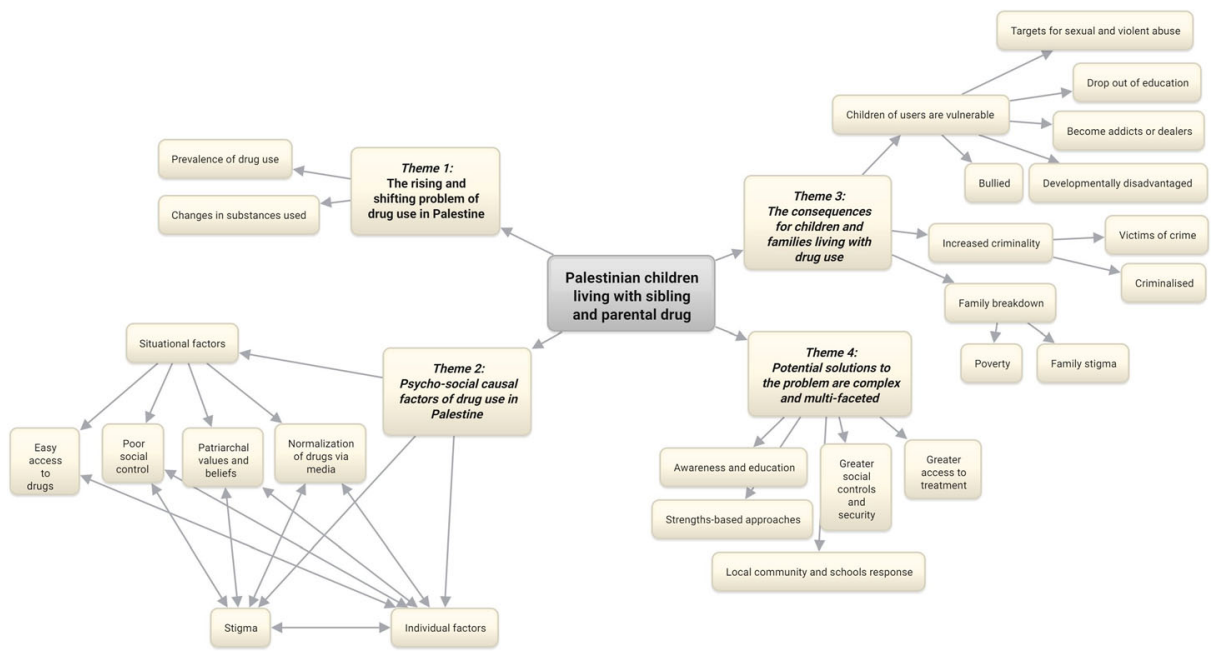

Fig. 1 Thematic map 'Palestinian Children living with sibling and parental drug use'

'witnessed the synthetic cannabinoids to be the most on demand substance in Palestinian streets, but addicts always use it with hashish, they smoke them together, so if an addict wants to quit from Hydro, they seek hashish' (Male Psychologist). Polysubstance use prevalence was reported across all discussions.

\section{Psychosocial Causal Factors of Drug Use in Palestine}

The lack of social and institutional controls within the OtP was described as predominant factors related to drug use. The political regime and occupation were discussed in the Bethlehem focus group; 'since 1995 until today, we did not become a Palestinian state and there was no improvement. This general political frustration led to the use of drugs, and recently they brought down the tax on alcoholic beverages ... encouraged drinking and stimulated using drugs' (Male Social Worker). This was echoed by the Jerusalem focus group, where participants alleged that 'this distribution and revolution is due to the occupation to keep the youth in coma and away from the Palestinian cause, so they help in the drugs revolution' (Male Social Worker). The occupation and regime appeared to have resulted in an insufficient and ineffective correctional system, whereby laws are not routinely implemented, meaning that services to support those within the correctional system or victims of crime fail. For example, participants from Bethlehem explained how drug dealers capitalise on the demand for drugs by exploiting the law: 'The Juvenile Law in 2016 considered those under 18 years as a victim and those under 15 considered as a special treatment other than the 15-18 year old. The law was very lenient with this category (under 15), so drug dealers got advantage from this law and exploited the children in trade, distribution, and others. This situation has an impact on the exploitation of children [sic]' (Male Officer in the Directorate of Juvenile and Family Protection).

The issue of poor social controls included local structures (e.g. schools; religious groups). Participants from Bethlehem agreed that the lack of follow-up when children dropped out of school meant that 'there is no observation and no awareness in schools, which increases the current drug situation' (Female Volunteer in the Palestinian Social and Psychological 
Professionals Association). Those from Ramallah felt the 'weakness of values and the absence of religious persuasion contributed greatly' (Female member and worker of the Al-Sadiq AlTaieb Association) to the drug problem. Most consistent across all four focus groups was the problem of family breakdown, when this was experienced, irrespective of its cause, this resulted in 'the end of the supervision of the children' and external peer influences on children became 'a group of bad friends...drag[ging] him to drugs as a way of releasing the pressure' (Male Psychologist Jerusalem group).

The ease at which Palestinian adults and young people can access drugs was a dominant theme across all focus groups. Several factors were discussed to explain this access, which include 'today there is a dealer in every village and corner, before; you had to travel to Jerusalem to specific places to get the substance... as well as cheap prices' (Male Psychologist and Educational Counsellor in Bethlehem); improved manufacturing and distribution channels means 'it is synthesized locally...in 2018 the West Bank territory became an area of cultivation of drugs through plantations' (Male Psychologist Jerusalem); vulnerable children are targeted by drug dealers 'in the promotion of drugs where the penalty is less because they are minors' (according to a male nurse working in the Psychiatry and Addiction unit in the Gaza Strip); and women and children are given drugs unwittingly, creating dependency and further demand.

All participants agreed that the media and improved technologies facilitated the normalisation of drug use, particularly among young people. In the Gaza Strip, participants reported that access to the 'internet and the proliferation of pornographic and corrupt sites is a major reason, especially after wide spread of smart mobile telephones' (Male Nurse). Those working in Jerusalem noted the sensationalisation of drugs and its effects through broader film and media outlets such as the 'internet, TV... Social media... Technology as the main factor' (Male AntiDrug Authority Officer) because 'children imitate what they see'.

Two of the four focus groups (Jerusalem and Bethlehem) reported how patriarchal values and beliefs contribute to the drug problem within Palestinian families. Blame, however, was placed on mothers who, in order to protect herself and her family, often hide the problem. One participant in Jerusalem reported how 'the mother is under pressure whether it was for sexual abuse or to keep the house together for the sake of her daughters' (Male Juvenile and Family Protection Police Department). Likewise, participants working in Bethlehem observed how mothers were blamed for failure to fully care for their children particularly when the father is absent: 'Mothers today doesn't [sic] take care of her children or follow them because she is busy. The absence of the role of the family and the absence of the father's authority contributes to the situation' (Male Anti-Drug Authority Officer).

While professionals in the Ramallah focus group suggested drug use as a developmental factor, in that adolescent drug users have a natural curiosity around experimentation; a range of individual factors related to substance abuse in Palestinian communities was described by all groups as interrelated with both situational factors and cultural stigma being factors. The choice to use drugs was primarily reported to be driven by people's sense of 'loss of hope... fear, psychiatric distress' or as a strategy to cope and 'escape problems' and obtain 'temporary relief' from the fear of violence, poverty and insecurity. Gender was observed by some participants as also determining drug activity and motivation for drug use. For instance, while men use drugs to heighten arousal for 'sexual reasons'; women use drugs to cope with sexual exploitation. In Jerusalem, women's addiction was described as 'linked to prostitution, if the female became addicted to it, then it will begin to interact with sex by using drugs so she will have a higher mood combining drugs and sex' (Male Anti-Drug Authority Officer). Drug use within women was observed to be strongly related to sexual abuse within the home, women 
and girls tended to be introduced to drugs 'usually by her husband if he was a user or her brother or even her father' (Male Anti-Drug Authority Officer). Indeed, participants from Ramallah noted how women and girls 'are mostly victims, whether friends or husband or employment or exploitation or others, I haven't seen a girl who started drugs on her own' (Male Anti-Drug Authority Officer) not only are they sexually abused but are at risk of being 'killed for her [drug] abuse' (Male Anti-Drug Authority Officer).

Stigma of the individual user and their family was observed as underpinning the challenges of help-seeking behaviours for addiction, and resulted in hidden use, and attempts to deal with the issue themselves. In Bethlehem, participants reported that 'parents know that their son is addicted, but they won't turn [sic] him to a rehabilitation centre' (Female Social Worker). In the Gaza Strip, they too recognised people not seeking treatment because of the 'stigma and its social dangers'. In Jerusalem, participants described how families 'usually kick the addict out' leading to 'family disintegration and stigma'. The issue of stigma is also highly gendered; whereby, a female addict 'is more rejected from society than male' (Male Social Worker in Bethlehem) and most treatment centres will not 'accept females unless it is a critical case' (Female Psychologist and Educational Counsellor). One of the reasons for this gender inequality discussed in all focus groups was that 'society blames women more and stigmatise her'. When a female is addicted to drugs, a Ramallah focus group participant stated, the family response was to hide the situation: 'They make sure to keep it confidential and no one knows because the topic of drugs is always related to ethics and honour. She may never get married and even her married sisters may become divorced. Their view is to protect the house and the family from the great shame she brought' (Female staff Ministry of Social Development).

While the stigma of addiction persists, according to two focus groups (Bethlehem and Ramallah), there appeared a shift in perspective on addiction to that of a medical issue in younger generations. Participants in the Bethlehem focus group reported a shift toward one of care and compassion, it was noted: 'if people knew this information about a person they will keep dealing with him, accept him and see him...the addict is a patient not a criminal... previously the addict hiding in shame and now he is declaring his using of drugs' (Female Social Worker).

\section{The Consequences for Children and Families Living with Drug Use}

All focus groups recognised the significant vulnerability of children living in a household with either a parent or sibling using drugs. One particular issue observed is that children were at risk of physical and sexual violence; 'inside the house violence may be implanted [sic] on them because the addicted father or adult is usually violent especially in the case of a missing dose, and resorts to beating his children' (Male officer in Juvenile and Family Protection in Ramallah). Those working in Bethlehem reported how 'kids are sexually assaulted...the child stops feeling safe in his family and the family becomes a source of fear. So, the child starts resorting to other people who may also exploit him' (Male Social Worker). In the Gaza Strip, one participant said; 'there have been several cases of sexual exploitation of children who have left school' (Male Primary school teacher).

Children dropping out of school to help support the economic needs of the family were described as another consequence of drug use within the family. Likewise, 'a lot of bullying is prevalent' in schools 'especially where the mother or father are addicted, is a targeted group and is exploited' (Female Psychologist in Jerusalem). Children were also observed to become addicts or drug dealers themselves when drug use is in the family. One participant in 
Bethlehem reported 'cases where the father exploited his children to bring drugs, promote and distribute, and because the influence of the father on children is great, they accidentally use drugs and become addicted' (Male Anti-Drug Authority Officer).

Children's social, emotional and psychological development was observed to become impaired when drug use is in the family. In Bethlehem, participants felt that through learnt behaviour and poor role modelling the 'disintegration of the personal structure of the child' leads 'to many problems in the future' (Male Psychologist and Educational Counsellor). In Jerusalem, a participant observed, particularly 'from the early years of age when he witnesses these behaviours, he will copy them' (Male Social Worker). The second consequence experienced by children and families was observed to be increased criminality, both in terms of becoming victims of crime as well as becoming criminalised themselves. Women and children are vulnerable to being victims of sexual and violent assaults, including murder. Examples were reported across all focus groups, for example, a woman was killed in Bethlehem by her husband 'with the knowledge of his family who didn't try to help' (Female Psychologist and Educational Counsellor). Violence was also viewed to be used to help fund drug use in the Gaza Strip, where there are 'criminal cases filed for thefts and armed robberies and in some cases, killing for the money to buy the drug' (Male Primary School Teacher) and Palestinian women are sexually exploited to secure finances or the safety of their family. Young people were viewed to be at risk of becoming criminalised. In Jerusalem, participants reported if the father breaks 'the law, he will be put away in jail'; therefore, children 'steal for the sake of getting money for house expenditure because there is no provider to depend on' (Male Juvenile and Family Protection Police Department). As children drop out of school, they turn to the streets to 'beg and steal' (Gaza Strip) or children themselves become part of the distribution chain and begin to deal drugs for others, they 'smuggle drugs because they are the most innocent category in society so a dealer can get use of this point' (Female Psychologist in Jerusalem) or, as reported in Bethlehem, this becomes part of the family norm as the 'father exploit(s) his children to bring drugs, promote and distribute' (Male Anti-Drug Authority Officer).

Drug use within Palestinian families appeared deeply connected with family disintegration; all focus groups described how families become unsafe and broken: 'The family of the addict is a sick family' (Male Psychologist and Educational Counsellor in Bethlehem). This destruction is caused by an 'absence of social security. This issue has affected all communities and families even good families because it has instilled fear for their children and others, the absence of laws' (Female Administrator in the Palestinian Social and Psychological Professionals Association) in which 'the impact of drugs on the economic situation is negative, in terms of their deviation due to unemployment and also affects security and safety and increase crime, it is all linked together' (Female Law Researcher Department of Social Development in Bethlehem). Those working in the Gaza Strip highlighted how 'many divorces are registered because of the husband's addiction and the resulting problems' (Male Pharmacist in the Psychiatric Department) which doubly stigmatises the family as 'the stigma of addiction affects the entire family and affects their social relationship, especially in marriage' (Female psycho social support in the Mental Hospital). As a result of this breakdown, children's futures are compromised which places jeopardy on the overall Palestinian family's financial security.

\section{Potential Solutions to the Problem Are Complex and Multi-Faceted}

Potential solutions to deal with the myriad of factors and challenges faced by drug-using families in Palestine were discussed. Awareness raising and education were a persistent theme. 
While awareness levels appear to be improving across the Gaza Strip and the West Bank, there remain challenges, requiring greater investment of effort across a range of domains, including education, health, family, religious communities and social media. In Jerusalem, one participant noted: 'the child in his early stages spends most of his time being at school, there comes the role of the Ministry of Education in strengthening the social workers and psychologists in staying in constant contact with children who suffer from this problem at home' (Male AntiDrug Authority Officer). Schools and educational institutions were viewed to be the most logical place to start early education around the harms of drug use, and other health concerns, such as smoking. Those working in the Gaza Strip argued that there is a real need because 'fighting child smoking... is widespread among them and is a major entry point for addiction' (Male Psychiatric Physician in the Mental Hospital). In addition to raising children's' awareness, the need for enhanced parenting support and family education was warranted. Those in Bethlehem suggested there ought to be 'awareness for their parents, they need to have training courses and awareness of how to deal with their children, how to become leaders and how to deal with the problem' (Female Administrator in the Palestinian Social and Psychological Professionals Association). Interventions were advised to be delivered in the family home, through 'visits to families in their homes in order to raise awareness to avoid the problem' (Female Psychologist and Educational Counsellor). One participant in Jerusalem stated that they should 'not raise awareness about the child alone but to the mother and father as well, and care about the psychological emptying of them. I want to work on the whole house with all its members not only the children' (Male Anti-Drug Authority Officer). Awareness regarding access to treatment and how treatment might help people is also required across the OtP, 'awareness shouldn't create intimidation, but...keep the message positive with a positive impact on the community' (female Ministry of Social Development in Ramallah).

Participants across all discussion in the West Bank and the Gaza Strip observed the need to improve security and develop greater social controls across the OtP, for example, through greater supervision in schools or in families. It was not clear how these controls might be operationalised; however, one participant in Jerusalem argued legal restraints are needed: 'Follow-up of parents to their children, when my son returns at 1am at night and I do not know where he was at that time, this is absolutely wrong, there must be a follow-up and strict laws in the house, so things are not left alone' (Male Juvenile and Family Protection Police Department). In Ramallah and Bethlehem, participants felt that children should be removed from the family and sent to 'institutions that foster children from families who are exposed and affected by the abuse of one parent' (Female Ministry of Social Development in Ramallah).

Improving access to treatment was highlighted, alongside the need for enhanced resourcing of drug rehabilitation centres. While primary health care and mental health clinics have begun to emerge in the Gaza Strip, drug rehabilitation centres do not appear to be a priority. Access and uptake to treatment were also observed to be dependent on gender and cost. Those in Bethlehem highlighted that one centre does not accept women causing 'injustice and stigma greater for females than males' (Female Psychologist and Educational Counsellor). While 'in Huda society, addicts were treated free of charge at the expense of the association' (Female Psychologist in Jerusalem), this is not the case for all provinces, focus groups suggested access to treatment should be free. Treatment for younger addicts was also advised to be targeted toward their needs in which professionals could 'work with families and children to receive services and subsequent care' (Female Law Researcher in Bethlehem).

All focus groups spoke about the need for greater investment in strength-based approaches to tackle the issue of drug use, particularly when attempting to help prevent children becoming 
addicts. Suggestions included 'youth-to-youth programs' (Gaza Strip) or peer mentoring schemes, which would provide 'good, trained friends within specific programs that pass certain behaviours to their peers. Passing a specific message from a peer to peer' (Male Social Worker in Jerusalem). Activities are required that would draw on the strengths and skills of young people helping them 'improve their skills and with other things that occupy them from the streets' (Female Psychologist and Educational Counsellor in Bethlehem); 'open sports clubs and amusement parks under the supervision of the officials' (Female Law Researcher in Bethlehem); and to 'take advantage of his energy in a positive way and expand his hobbies' (Male Anti-Drug Authority Officer in Jerusalem). Not only would these approaches help children's development, but these may help them deal with some of the problems and challenges they face within their communities 'finding clubs or places reserved for children for extracurricular activities where they are trained on how they face the problem' (Male Social Worker in Jerusalem). Participants wanted to capitalise on the free time children have by occupying their time productively exploiting all opportunities by 'teaching them professions, activities, ideas and organise their time toward the positive side to avoid their falling addiction' (Female Administrator in the Palestinian Social and Psychological Professionals Association); 'kill leisure time, and register them in clubs and activities' (Male Officer in the Directorate of Juvenile and Family Protection in Bethlehem); 'intensify youth camps especially in the summer' (Male Pharmacist in the Psychiatric Department in the Gaza Strip); and 'after school there is a lot of free time and in the summer vacation as well, so we have to support the idea of summer camps' (Male Social Worker in Jerusalem). One of the key messages was best summed up by one Jerusalem participant who noted that young people 'are like a tree, if we water it right it bears fruit, but if we neglect it, it will be dry' (Male Anti-Drug Officer).

\section{Discussion}

There has been little research or response activity to Palestinian children's unique needs relating to trauma and vulnerabilities caused by drug abuse in the home United Nations Office for Drugs and Crime (UNODC) 2019; (Van Hout et al. 2019). This unique study represents a first attempt to understand the issue from the perspectives of those working in the field and highlights the urgent need to respond to the needs of Palestinian children exposed to drug abuse in the home. The impact of drug abuse on these children, their siblings and their parents is significant, notwithstanding the existing traumas, instability and conflict in the OtP.

The situation of children and their mothers is exacerbated by the hidden nature of drug abuse within their families. This focus group study underpins and expands the evidence base highlighted in the team's review of literature (Van Hout et al. 2019). They continue to paint a concerning picture of families being subjected to multiple pressures and exposed to a multitude of risks including use of drugs as a coping mechanism for trauma, stigmatisation for that drug use, restricted access to services, family breakdown, sexual abuse, criminality and lack of agency over day to day existence. Of particular concern is the stigma experienced by women (and mothers) using drugs, many of whom have experienced multiple trauma including sexual assault, which adds to an already long list of additional pressures for them which may add to their rationale for using drugs. When these women feel unable to access support, the fall out includes inevitable suffering and increased risk for their children who will have already experienced trauma themselves through the occupation. 
Some of the issues are not wholly different to the issues currently facing communities across the world. For instance, focus groups noted the increased presence of NPS, a relatively recent phenomenon even in affluent Western countries, which demonstrates that the market for illicit substances is evolving as rapidly in the OtP as elsewhere, and this in itself creates new issues for authorities, not least because of the lack of evidence for long-term use of such substances (Mounteney et al. 2016). Added to stigma (Defence for Children International/ Palestine Section 2007; Damiri et al. 2018a; Van Hout et al. 2019;, the poor social services, social and political tensions and inability of the Palestinian law enforcement to police the influx of drugs into the West Bank, East Jerusalem and Gaza compound the issue (Massad et al. 2016). The perceived similarity between the Palestinian and Israeli drug markets highlights the ease with which substances are entering the Palestinian areas and the probability that, because of the blockade, drugs are entering the OtP through Israeli routes whether official (a concern raised by some participants) or not. Some discussion in focus groups highlighted the negative consequence of reduced punishments for children who were caught selling illicit substances, although the evidence is that by decriminalising or lessening penalties for drug use at least, this has benefits to societies as they treat drug use as a health issue rather than a criminal issue (Volkow et al. 2017). This is evidenced in the current Palestinian Drug Law referring to the drug addict as a patient not a criminal, and makes it more likely that the individual concerned would seek help for their drug use if they viewed it as becoming problematic, and for parents, this would have the knock-on effect of limiting the potential for damage to their wider families. In Bethlehem, this was becoming the case increasingly, and the benefits of this approach might encourage other regions to facilitate non-punitive programmes. This is particularly of interest given the recent 2019 opening of the PNRC in Bethlehem which provides free drug dependence treatment to women and men (United Nations Office for Drugs and Crime (UNODC) 2019). Improving access to treatment would also be beneficial to the population, but the financial constraints placed on operation of support systems to Palestinians by the Israeli authorities make expanding this kind of activity more difficult.

Of greater importance is the general lack of social structures noted such as schools or religious groups, which provide less opportunity for engagement and greater opportunity for individuals to seek other forms of past times in the absence of contact with other people in these settings. This is again not unique to the OtP, as cuts to education or social support structures due to austerity have proven in other countries (Abramsky 2019), but the pressures on Palestinian infrastructure and its social structures are clearly impacting on more than just education or religious practice. The identified family breakdown, which has been a consistent theme of Palestinian life for many years, provides one less fall-back support structure for individuals already living without a safety net. However, because of the importance placed on social structures, they can also cause damage in terms of stigma for individuals who fall outside of those defined boundaries, and this is clearly a barrier to families accessing help when needed. This stigma may be more prominent in predominantly Muslim societies (Arfken and Ahmed 2016).

Problematic substance use can often be a coping mechanism for pressures on an individual experienced through the conditions in which they live. While suggestions around potential solutions focussed on control strategies, it is difficult to believe that reducing the use of drugs would be possible to any great extent in a country which has experienced long-term occupation with regular conflict, and the trauma that this engenders in children from an early age. Substances including heroin have been used for instance by personnel in areas of conflict globally over a long period of time as a way of coping with the horror of violence, and this is 
recognised by one of the participants who explained drug use by 'loss of hope...fear [and] psychiatric distress', but most people using drugs in areas of conflict cease when removed from that combat zone (Robins et al. 2010). While Palestinian children experience trauma on a daily basis through their lived experience of the occupation which leads to substance use, it may still be possible to reduce the harms associated with drug use by emphasising education around types of substances, routes of administration and the effect on mental health. This was recognised by discussion here of the various mediums in which education and awareness could take place, and particularly using social media channels can be a way of cost effectively disseminating health messages to younger people through peer-to-peer sharing (Evans et al. 2017). Visits to households by health visitors would also be beneficial but could be labour intensive if not focussed on particular sections of the population; however, training for existing staff around substance use would potentially be a feasible action. Removing children from Palestinian families with problematic substance use on the other hand could adversely affect the child if they experience detachment from their families from this process and control strategies for substance use have regularly had poor outcomes associated with them (Maciel and de Vargas 2015).

While some of these interventions may be helpful, the context is an occupation and blockade which is causing substantial suffering to the population and some focus group members indeed believed that the high levels of drug use were part of a strategy of population control. Children regularly experience multiple adverse childhood experiences (ACEs) including depression, anxiety and associated post-traumatic stress disorder (PTSD) which are all well-known risk factors for heightened levels of drug use, and this was acknowledged too by the focus groups (Volpe et al. 2017). The role of ACEs within an environment of occupation and political violence remains unstudied and may be key to developing effective intervention that promotes resilience within this young vulnerable population in the OtP. Attempting to reduce harm while not tackling the underlying causes of why individuals might use a substance will at best provide small benefits to the person concerned and the wider family. Because this area is under-researched, it is a hidden and very stigmatised social problem in Palestinian society, as this is only a small qualitative study of frontline professional perspectives, it is difficult to make generalisations but the speed at which participants felt the situation had escalated over the last few years in the OtP. We recognise this means that action is needed now to prevent further escalation of the issues concerned. At a time when civil society is considered by some to be at breaking point and the recent 'right to return' protests were described by the United Nations as 'a call for help from a population in despair' (United Nations/The question of Palestine 2019), it is clear that inaction on this issue may contribute to further social unrest for an already besieged population.

\section{Conclusion}

The continued political and economic tensions and dense populations living in the West Bank and Gaza Strip have compounded the impact of drug abuse and addiction in the home. This unique study has illustrated the experiences of professionals working with Palestinian families and children affected by substance use and addiction in the home. It paints a concerning picture of how drug abuse impacts on Palestinian children, mothers and parents subjected to multiple pressures, stigmas, risks and harms relating to their situation, and underscores the urgent need for a united and strategic response. 
Funding Information The study was funded by the Global Challenges Research Fund (GCRF) Small Grants Scheme 2019, Liverpool John Liverpool John Moore's University, 2019 to Professor Marie Claire Van Hout.

\section{Compliance with Ethical Standards}

Conflict of Interest The authors declare that they have no conflict of interest.

Open Access This article is distributed under the terms of the Creative Commons Attribution 4.0 International License (http://creativecommons.org/licenses/by/4.0/), which permits unrestricted use, distribution, and reproduction in any medium, provided you give appropriate credit to the original author(s) and the source, provide a link to the Creative Commons license, and indicate if changes were made.

\section{References}

Abramsky, S. (2019). The price of austerity in England. Nation, 308(8), 22-25.

Al-Afifi, M. F., Sakka, M., Shehada, M., \& Afifi, R. (2015). Effect of Gaza 2014 war on use of smoking, tramadol, and psychoactive drugs among university students. Retrieved from https://www.drugabuse. gov/international/abstracts/effect-gaza-2014-war-use-smoking-tramadol-psychoactive-drugs-amonguniversity-students. Last accessed on 1 July 2019.

Arfken, C. L., \& Ahmed, S. (2016). Ten years of substance use research in Muslim populations: where do we go from here? Journal of Muslim Mental Health, 10, 1. https://doi.org/10.3998/jmmh.10381607.0010.103.

Braun, V., \& Clarke, V. (2006). Using thematic analysis in psychology. Qualitative Research in Psychology, 3(2), $77-101$.

Braun, V., Clarke, V., Hayfield, N., \& Terry, G. (2019). Thematic analysis. Handbook of research methods in health social sciences (pp. 843-860). https://doi.org/10.1007/978-981-10-5251-4_103.

Clarke, V., \& Braun, V. (2018). Using thematic analysis in counselling and psychotherapy research: a critical reflection. Counselling and Psychotherapy Research, 18(2), 107-110.

Damiri, B. R., Isra'A, S., \& Aghbar, M. H. (2018a). Pattern of substance use among schoolchildren in Palestine: a cross-sectional study. Egyptian Journal of Forensic Sciences, 8(1), 59.

Damiri, B., Sayeh, W., Odeh, M., \& Musmar, H. (2018b). Drug use and possession, emerging of new psychoactive substances in the West Bank, Palestine. Egyptian Journal of Forensic Sciences, 8(1), 42.

Defense for Children International/Palestine Section. (2006). Trends of educational counselors on child abuse: field study in schools of the Palestinian National Authority. Retrieved from https://arabic.dci-palestine. org/ dcipal/sites/arabic.dci-palestine.org/files/childabuse.pdf. Last accessed on 2 July 2019.

Defense for Children International/Palestine Section. (2007). Children in street: the Palestinian case. Retrieved from https://arabic.dci-palestine.org/ dcipal/sites/arabic.dci-palestine.org/files/childreninthestreetarabic.pdf. Last accessed on 2 July 2019.

Etikan, I., Musa, S. A., \& Alkassim, R. S. (2016). Comparison of convenience sampling and purposive sampling. American Journal of Theoretical and Applied Statistics, 5(1), 1-4.

Evans, W., Andrade, E., Goldmeer, S., Smith, M., Snider, J., \& Girardo, G. (2017). The living the example social media substance use prevention program: a pilot evaluation. JMIR Mental Health, 4(2), e24.

Glick, P., Al Khammash, U., Shaheen, M., Brown, R., Goutam, P., Karam, R., et al. (2018). Health risk behaviours of Palestinian youth: findings from a representative survey. EMHJ-Eastern Mediterranean Health Journal, 24(02), 127-136.

Kallio, H., Pietilä, A., Johnson, M., \& Kangasniemi, M. (2016). Systematic methodological review: developing a framework for a qualitative semi-structured interview guide. Journal of Advanced Nursing, 72(12), 2954-2965.

Maciel, M. E. D., \& de Vargas, D. (2015). Harm reduction: an alternative to the failure of the war on drugs. Cogitare Enferm, 20(1), 205-208.

Massad, S. G., Shaheen, M., Karam, R., Brown, R., Glick, P., Linnemay, S., \& Khammash, U. (2016). Substance use among Palestinian youth in the West Bank, Palestine: a qualitative investigation. BMC Public Health, $16(1), 800$.

Mounteney, J., Griffiths, P., Sedefov, R., Noor, A., Vicente, J., \& Simon, R. (2016). The drug situation in Europe: an overview of data available on illicit drugs and new psychoactive substances from European monitoring in 2015. Addiction, 111(1), 34-48.

Nowell, L. S., Norris, J. M., White, D. E., \& Moules, N. J. (2017). Thematic analysis: striving to meet the trustworthiness criteria. International Journal of Qualitative Methods, 16(1), 1609406917733847. 
Palestinian Central Bureau of Statistics (PCBS). (2018). Press report on the Labour Force Survey results. Ramallah - Palestine. Retrieved from https:/www.pcbs.gov.ps/portals/_pcbs/PressRelease/Press_En_13-22019-LF-e.pdf. Last accessed on 2 July 2019.

Palestinian National Institute of Public Health. (2017a). Estimating the extent of illicit drug use in Palestine. Retrieved from https://www.unodc.org/documents/middleeastandnorthafrica/Publications/Estimating_the Extent_of_Illicit_Drug_Use_in_Palestine.pdf. Last accessed on 2 July 2019.

Palestinian National Institute of Public Health. (2017b). Illicit drug use in Palestine. Retrieved from https://www. unodc.org/documents/publications/Illicit Drug Use in Palestine.pdf. Last accessed on 2 July 2019.

Robins, L., Helzer, J., Hesselbrock, M., \& Wish, E. (2010). Vietnam veterans three years after Vietnam: how our study changed our view of heroin. The American Journal on Addictions, 19(3), 203-211.

Smithson, J. (2000). Using and analysing focus groups: limitations and possibilities. International Journal of Social Research Methodology, 3(2), 103-119.

Sweileh, W. M., Arafat, R. T., Al-Khyat, L. S., Al-Masri, D. M., \& Jaradat, N. A. (2004). A pilot study to investigate over-the-counter drug abuse and misuse in Palestine. Saudi Medical Journal, 25(12), 2029-2032.

Thabet, A. A. M., \& Dajani, J. K. (2012). Substance abuse among Palestinians in the West Bank and Gaza Strip. Arab Journal of Psychological Science, 36, 76-78.

United Nations Office on Drugs and Crime (UNODC). (2019). Independent Evaluation of PSEY13. Supporting the establishment of evidence-based drug dependence treatment and rehabilitation system for the Palestine National Rehabilitation Centre. Retrievd from https://www.unodc.org/documents/evaluation/Independent Project_Evaluations/2019/PSEY13_Final_Independent_Project_Evaluation_Jan_2019.pdf. Last accessed on 2 July 2019.

United Nations/The question of Palestine. (2019). The UN independent commission of inquiry on the 2018 Gaza protests. Retrieved from https://www.un.org/unispal/document/un-independent-commission-of-inquiry-onprotests-in-gaza-presents-its-findings-press-release/. Last accessed on 2 July 2019.

Van Hout, M. C., Al-Afifi, M. F., Abushams, L., Kewley, S., Quigg, Z., Whitfield, M., et al. (2019). Palestinian children's experiences of drug abuse in the home in the occupied territories of Palestine: a scoping review of extant literature. International Journal of Mental Health and Addiction, 1-14. https://doi.org/10.1007 /s11469-019-00085-2.

Volkow, N. D., Poznyak, V., Saxena, S., Gerra, G., \& Network, U. I. I. S. (2017). Drug use disorders: impact of a public health rather than a criminal justice approach. World Psychiatry, 16(2), 213-214.

Volpe, E. M., Rodriguez, L., \& Read, J. P. (2017). The relationship between trauma and PTSD and the influence of alcohol and drug use. In Alcoholism-clinical and experimental research (Vol. 41, p. 148A). Hoboken: Wiley.

Waterston, T., \& Nasser, D. (2017). Access to healthcare for children in Palestine. BMJ Paediatrics Open, 1(1).

Publisher's Note Springer Nature remains neutral with regard to jurisdictional claims in published maps and institutional affiliations.

\title{
Affiliations
}

\section{Mohammed Al-Afifi ${ }^{1} \cdot$ Leen Abushams ${ }^{2} \cdot$ Mazen Sakka $^{1} \cdot$ Maha Shehada $^{1} \cdot \operatorname{Riad}$ Afifi $^{1}$ • Majed Alloush ${ }^{3}$ - Afaf Rabee ${ }^{3} \cdot$ Stephanie Kewley $^{4} \cdot$ Zara Quigg $^{5} \cdot$ Mark Whitfield $^{5} \cdot$ Jim McVeigh $^{5}$ - Mayyada Wazaify ${ }^{2}$ - Marie Claire Van Hout ${ }^{5}$}

\author{
Mohammed Al-Afifi \\ m.afifi47@gmail.com
}

Leen Abushams

leen_abushams@hotmail.com

Mazen Sakka

sakkamazen@gmail.com

Maha Shehada

maha702000@gmail.com

Riad Afifi

afifiriad@gmail.com 
Majed Alloush

al_sadiq22000@yahoo.com

Afaf Rabee

afafrabee@yahoo.com

Stephanie Kewley

s.kewley@ljmu.ac.uk

Zara Quigg

z.a.quigg@ljmu.ac.uk

Mark Whitfield

m.whitfield@ljmu.ac.uk

Jim McVeigh

j.mcveigh@ljmu.ac.uk

Mayyada Wazaify

m.wazaify@ju.edu.jo

1 Substance Abuse Research Centre (SARC), Gaza, Palestine

2 School of Pharmacy, University of Jordan, Amman, Jordan

3 Al-Sadiq Al-Taieb Association, Ramallah, Palestine

4 School of Science, Liverpool John Moore's University, Liverpool, UK

5 Public Health Institute (PHI), Liverpool John Moore's University, Liverpool, UK 